\title{
The effect of minimum quantity lubrication in the intermittent turning of magnesium based on vibration signals
}

\author{
D. Carou ${ }^{1,2 *}$, E.M. Rubio ${ }^{3}$, C.H. Lauro ${ }^{2}$ and J.P. Davim $^{2}$ \\ *Corresponding author: D. Carou, e-mail: diecapor@gmail.com \\ ${ }^{1}$ School of Mechanical and Materials Engineering, University College Dublin, Belfield, Dublin 4, Dublin, Ireland \\ ${ }^{2}$ Dept. of Mechanical Engineering, University of Aveiro, Campus Santiago, 3810-193, Aveiro, Portugal \\ ${ }^{3}$ Dept. of Manufacturing Engineering, Universidad Nacional de Educación a Distancia (UNED), C/ Juan del Rosal, \\ 12, E28040-Madrid, Spain
}

\begin{abstract}
The present work shows an experimental investigation on intermittent turning based on vibration signals. The dependence of vibrations on the feed rate, minimum quantity lubrication (MQL) flow rate and the type of the interruption of the workpiece is evaluated. The results indicate that a part of the vibrations depends on the flow rate of the MQL system and its interaction with the feed rate, finding no dependency on the type of interruption. The influence of the MQL system is greater when machining at the lower feed rate. In addition, a strong relation between surface roughness and vibrations is identified. However, this relation is quite different depending on the environment used. In general, under dry conditions, the higher the vibrations the higher the surface roughness, while the opposite occurs when the MQL system is used.
\end{abstract}

Keywords: dry machining, intermittent turning, magnesium, MQL system, vibration.

\section{INTRODUCTION}

Since the late 1980s the use of light materials is attracting a great attention because of their suitability to improve the fuel economy [1]. Among main lightweight materials, the use of magnesium has being increased due to its low density and other properties such as its specific strength, good castability [2] and good damping capacity [3]. Automotive industry is one of the main sectors in which magnesium is being used in applications such as transmission casings, valve covers, intake manifolds, brackets or pumps [4], but magnesium is also finding applications in industries such as aerospace, electronics and biomedical devices [5].

Magnesium alloys are easy to machine when considering the power required, attainable cutting speeds and expected tool life compared to other usual structural materials [6]. Good surface finish can be achieved in magnesium machining [7]. However, there are several problems to consider in magnesium machining such as the ignition risk and its reactivity with water [8].

Surface integrity, particularly, the surface topography plays a major role on the final functional performance of the machined components in terms of fatigue resistance, surface friction, wearing, light reflection and heat transmission $[9,10]$. A wide range of parameters are identified by Zhang et al. [11] as influential factors for surface roughness in ultra-precision machining. Among them, cutting conditions (cutting speed, depth of cut and feed rate) have been widely analysed. Other factors are the machine tool, tool geometry, 
environmental conditions, material property, chip formation, tool wear and vibration.

To achieve a good surface quality, it is required to guarantee the stability of the machine tool and workpiece set-up [12]. According to Thomas and Beauchamp [13], the machined surfaces consist of two superimposed profiles: the theoretical profile due to operation kinematics and a dynamic profile due to cutting-edge vibrations. Thus, the analysis of vibrations is of great importance to reach a better understanding of the surface roughness produced.

Generally, the vibrations in the turning process can be classified into three categories: free vibration, forced vibration and self-excited vibration [14]. Certain combinations of machining parameters generate process instabilities that produce a high level of vibrations which in turn results in a decrease in accuracy, inferior surface finish, reduced tool life time and lower metal removal rate [15]. Typically, vibrations are analysed using sensors such as accelerometers and dynamometers [16]. For instance, Thomas and Beauchamp [13] analysed the vibrations to evaluate the influence of different cutting variables (cutting speed, depth of cut and feed rate), tool variables (tool nose radius and tool length) and workpiece length on the tool vibration generated in turning by means of a statistical analysis based on 288 tests. Another noteworthy study was conducted by Stoic et al. [17]. In the study, surface roughness is identified as a consequence of both cutting disturbances and the tool/workpiece non-uniform loading distribution. Authors stated that force measurements are preferred for low frequencies and acceleration measurements at high frequencies. Lee et al. [14] recognised the different behaviour in terms of vibrations of two different materials: S45C steel and 6061 aluminium when turned, presenting a vibration absorber method to diminish the vibrations generated. Upadhyay et al. [18] developed a prediction model using cutting parameters and vibrations as input to predict surface roughness. They developed models as a function of the vibration amplitude (radial, axial and tangential directions), obtaining an average percentage error of $4.11 \%$ and maximum percentage error of 6.42\%. Hessainia et al. [19] studied the surface roughness in hard turning, evaluating the influence of the cutting parameters and vibrations measured in the main and radial cutting force directions. In the study, a strong relation between surface roughness and cutting parameters, mainly feed rate, was found, while vibrations were found to be non-significant in the Analysis of Variance performed. Abouelatta and Mádl [20] predicted the surface roughness based on cutting parameters and tool vibrations, stating that the prediction is better when the model includes tool vibrations.

Nowadays, a large number of industrial parts present some kind of interruption on their surfaces [21]. Discontinuous cutting is characterised by the existence of thermal cycles and continuous mechanical impacts between the tool and workpiece [22] that can lead to the failure of the tool due to several mechanisms [23].

The selection of an adequate cooling/lubricating strategy is an important topic in magnesium machining. Several alternatives have been investigated in the past such as cryogenic refrigeration [7,24], dry machining [25] and minimum quantity lubrication (MQL) [26]. Among these strategies, the MQL system has proved to be a good alternative as, for instance, showed the study by Dhar et al. [27]. In their study, authors identified a beneficial effect of the MQL system over dry machining and wet cooling when assessing the surface roughness. 
Although magnesium has been extensively used in the last decades by different industrial sectors, the research in magnesium machining is still limited. Particularly, the effect of different cooling/lubricating systems on the outputs of the process requires further research. Moreover, most of the research in turning processes is focused on continuous processes analysing mainly the influence of the cutting conditions.

The present study analyses the intermittent turning of the UNS M11917 magnesium alloy, evaluating the influence of the vibrations measured during the process. The main objectives of the study include the assessment of the influence of the MQL system and the discontinuity of the surfaces on the vibrations measured and their relation to the surface roughness.

\section{EXPERIMENTAL PROCEDURE}

\subsection{Materials and equipment}

Turning tests were performed in a Kingsbury MHP 50 CNC lathe using as cooling system the Coolubricator $\mathrm{JR}^{\mathrm{TM}}$ MQL UNIST equipment. The MQL system used the r.rhenus NOR SSL cutting fluid, specially recommended for the machining of magnesium. The nozzle of the MQL system was directed to the tool-rake in form of mist, using an air pressure of $0.6 \mathrm{MPa}$, and placed at a short distance from the tool. Inserts used were cemented carbide inserts from Sandvik Coromant (TPGN 160304 H13A), using the CTGPL 2020 K16 (ISO) tool holder from Sandvik Coromant (Table 1).

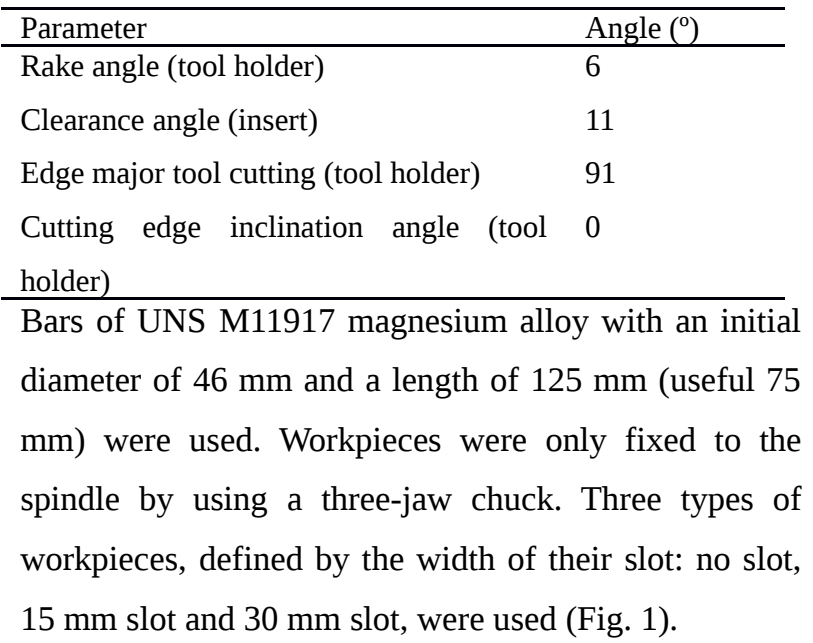
workpieces, defined by the width of their slot: no slot, $15 \mathrm{~mm}$ slot and $30 \mathrm{~mm}$ slot, were used (Fig. 1).

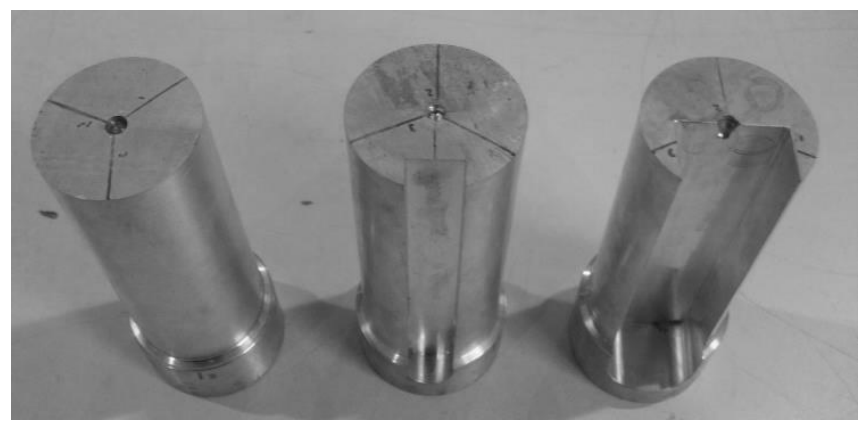

Fig. 1. Types of workpieces.

To evaluate the surface roughness, a Hommel Tester T1000 profilometer connected to a PC by the RS-232 interface and the Turbo-Datawin software were used. To monitor the vibration signal, a shock accelerometer Dytran $^{\mathrm{TM}}$ model 3200B (sensitivity of $0.05 \mathrm{mV} / \mathrm{g}$ ), see Fig. 2, and a Signal Conditioners/Vibration Meters Dytran $^{\mathrm{TM}}$ model 4102C were used. The data acquisition was developed using the LabVIEW ${ }^{\mathrm{TM}}$ software and the interface to PC used a National Instruments ${ }^{\mathrm{TM}}$ connector block model BNC-2120 and I/O card PCI 643.

\section{Table 1.}

Geometry of the insert and tool holder. 


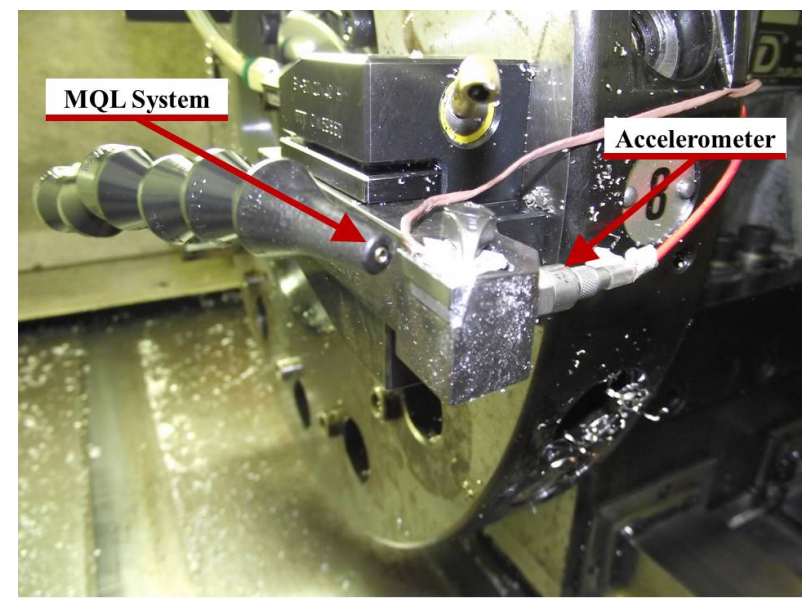

Fig. 2. Set-up: accelerometer and MQL system.

The accelerometer was installed at the side of the tool holder (feed direction). It was positioned to acquire the vibration caused by the MQL system, see Fig. 3.

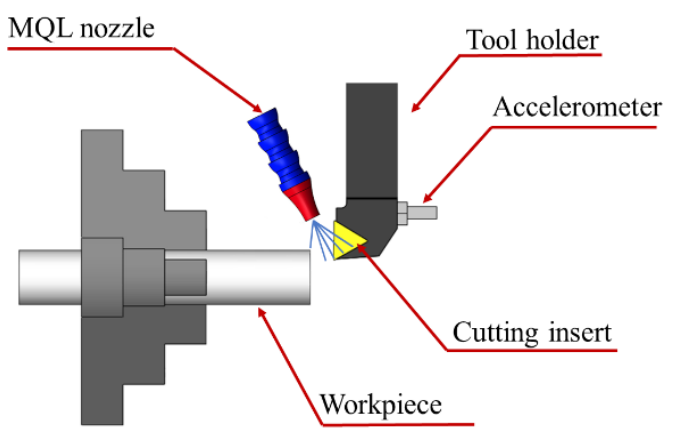

Fig. 3. Set-up of the turning process.

The signal acquisition was developed applying a Butterworth filter to reduce the disturbances and using a sampling frequency defined at $1000 \mathrm{~Hz}$. To compare the different conditions, the vibration signals were analysed in time domain through the root mean square (RMS) technique.

\subsection{Methodology}

The main objective of the experiment is the analysis of the influence of the MQL system in the intermittent turning of magnesium alloys by means of the vibration signals. As output of the process, the surface roughness was selected. The feed rate $(f)$ is recognised to have an important influence on the surface roughness in turning processes. In particular, both feed rate and tool nose radius are the only parameters included in the theoretical models for surface roughness [28]. However, the results of these experimental models differ from the ones obtained in experimental tests, being the vibrations a possible reason to explain these differences [29]. In addition, the use of cooling/lubricating systems such as the MQL system has important effects in the machining process, for instance, in terms of friction and temperature, but it can also have significant influence in terms of vibrations.

To develop the research, an experimental plan that identifies several factors to study based on other studies [30] is established (Table 2). The main factors considered are: feed rate $(f), \mathrm{MQL}$ flow rate $(c)$ and type of interruption (i). The values selected for these factors were: 0.1 and $0.2 \mathrm{~mm} / \mathrm{rev}, 0$ (dry machining) and 30 $\mathrm{ml} / \mathrm{h}$, and 0, 15 and $30 \mathrm{~mm}$ for the feed rate, MQL flow rate and type of interruption, respectively.

The selection of cutting parameters, especially the depth of cut and spindle speed, plays an important role in the appearance of chatter in the turning process. In particular, the appearance of chatter is less likely, depending on the spindle speed when turning using low depths of cut [31]. Tool vibrations are expected to be higher when high values of depth of cut are used [13]. Thus, all of the tests are performed with a depth of cut $\left(a_{p}\right)$ of $0.25 \mathrm{~mm}$ and a fixed cutting speed $\left(v_{c}\right)$ of 200 $\mathrm{m} / \mathrm{min}$ (initial spindle speed of 1,384 rpm) to diminish the likelihood of the appearance of chatter.

Both dry machining and MQL conditions are tested using a machining length $(l)$ of $25 \mathrm{~mm}$. The following objectives are established for the research:

a) Analysis of the influence of the feed rate, MQL flow rate and type of interruption on the vibration signals. 
b) Evaluation of the relation between the vibration signals and the surface roughness of the machined workpieces.

Table 2.

Experimental plan.

\begin{tabular}{|c|c|c|c|c|c|}
\hline Test & $\begin{array}{l}f \\
(\mathrm{~mm} / \mathrm{rev})\end{array}$ & $\begin{array}{l}v_{c} \\
(\mathrm{~m} / \mathrm{min})\end{array}$ & $\begin{array}{l}l \\
(\mathrm{~mm})\end{array}$ & $\begin{array}{l}a_{p} \\
(\mathrm{~mm})\end{array}$ & $\begin{array}{l}C \\
(\mathrm{ml} / \mathrm{h})\end{array}$ \\
\hline 1 & 0.2 & 200 & 25 & 0.25 & 0 \\
\hline 2 & 0.1 & 200 & 25 & 0.25 & 0 \\
\hline 3 & 0.2 & 200 & 25 & 0.25 & 0 \\
\hline 4 & 0.1 & 200 & 25 & 0.25 & 0 \\
\hline 5 & 0.2 & 200 & 25 & 0.25 & 30 \\
\hline 6 & 0.1 & 200 & 25 & 0.25 & 30 \\
\hline 7 & 0.2 & 200 & 25 & 0.25 & 30 \\
\hline 8 & 0.1 & 200 & 25 & 0.25 & 30 \\
\hline
\end{tabular}

\section{RESULTS AND DISCUSSION}

\subsection{Influence of the cutting parameters}

When observing the use of the MQL system, the vibration signal in the air cutting was about 20 times higher than in dry conditions. However, the values of the vibration when using the MQL system fell greatly during the cutting, see Fig. 4. The values of the vibration signal are listed in Table 3.

a)

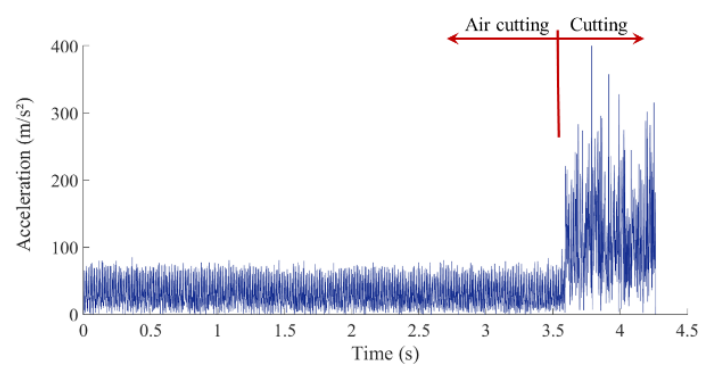

b)

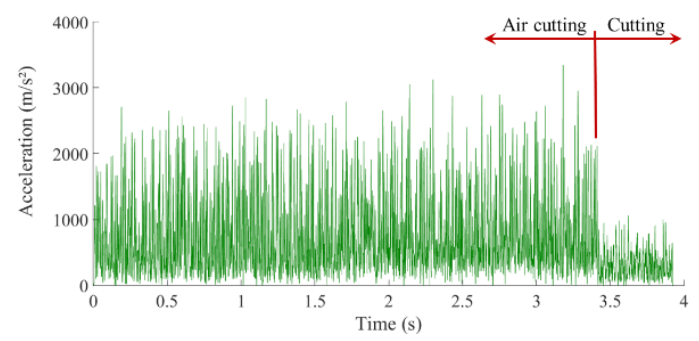

Fig. 4. Air cutting signal acquisition in a) dry machining, b) MQL system.

Table 3.

Acceleration results obtained in the tests.

\begin{tabular}{llll}
\hline Test & \multicolumn{3}{c}{ Acceleration $\left(\mathrm{m} / \mathrm{s}^{2}\right)$} \\
& $i=0 \mathrm{~mm}$ & $i=15 \mathrm{~mm}$ & $i=30 \mathrm{~mm}$ \\
\hline 1 & 154.63 & 148.85 & 125.89 \\
2 & 77.45 & 74.99 & 67.30 \\
3 & 150.13 & 143.25 & 127.05 \\
4 & 75.87 & 75.51 & 67.15 \\
5 & 296.83 & 267.09 & 215.09 \\
6 & 62.26 & 1267.04 & 1294.07 \\
7 & 215.09 & 157.52 & 134.85 \\
8 & 1314.41 & $1267.05^{*}$ & 1284.30 \\
\hline
\end{tabular}

Based on the results shown in Table 3, a multiple linear regression model [32] is established to analyse the acceleration results. The multiple linear regression model is performed based on Eq. (1) where only the main factors and the single interactions among them are considered:

$$
y=\beta_{0}+\beta_{1} . f+\beta_{2} . i+\beta_{3} . c+\beta_{4} . f * i+\beta_{5} . f * c+\beta_{6} . i * c+\varepsilon(1)
$$

where $y$ is the amplitude of the vibration; $\beta_{0}$ is the intercept; $\beta_{1}, \beta_{2}$ and $\beta_{3}$ represent the estimates of the feed rate, type of interruption and MQL flow rate; $\beta_{4}, \beta_{5}$ and $\beta_{6}$ the estimates of the interactions: feed rate*type of interruption, feed rate*MQL flow rate and type of interruption*MQL flow rate, respectively; and, $\varepsilon$ represents the error of the model. The results for the 
model are calculated using the R statistical program and are listed in Table 4.

The results of the multiple linear regression model allow identifying the significant factors and interactions according to their p-value (right-column). Considering a significance level $(\alpha)$ of 0.05 [33], only the MQL flow rate and the interaction between the MQL flow rate and the feed rate are significant factors. Particularly, the statistical analysis shows that the type of interruption has no significant influence on the results. Thus, it is predicted that, at least at low machining conditions, in the intermittent machining of magnesium alloys the continuous entrance and exit movements of the tool will not lead to higher vibration levels. However, it must be stated that the model did not explain completely the variability of the measured vibration signals in all the tests, though high multiple R-squared (0.809) and adjusted R-squared (0.7416) values were obtained.

\section{Table 4.}

Estimators for the model.

\begin{tabular}{lllll}
\hline & Estimate & $\begin{array}{l}\text { Std. } \\
\text { Error }\end{array}$ & t value & $\operatorname{Pr}(>|t|)$ \\
\hline Intercept & -248.6 & 300.7 & -0.827 & 0.419855 \\
$f$ & 2431.7 & 1862.2 & 1.306 & 0.209010 \\
$c$ & 1805.4 & 337.5 & 5.348 & $5.32 \mathrm{e}-05$ \\
$i$ & 253.0 & 202.2 & 1.252 & 0.227655 \\
$f^{*} c$ & -9357.0 & 1990.8 & -4.700 & 0.000206 \\
$f^{*} i$ & -1745.8 & 1219.1 & -1.432 & 0.170261 \\
$c^{*} i$ & 138.8 & 121.9 & 1.139 & 0.270674 \\
\hline \multicolumn{5}{r}{ Residual standard error: 243.8 on 17 degrees of freedom }
\end{tabular}

Multiple R-squared: 0.809, Adjusted R-squared: 0.7416

F-statistic: 12 on 6 and 17 DF, p-value: 2.653e-05

The average vibrations results are plotted versus the feed rate in Fig. 5, using two series of data for dry machining and MQL conditions and for the three workpieces used. In the figures, for dry machining, it is possible to appreciate a clear influence of the feed rate on the vibrations. As the feed rate increases, the vibrations also increase. The feed rate is also identified as a source of vibrations in the study by Thomas and Beauchamp [13]. Regarding the type of interruption, no clear influence is identified as it was concluded in the statistical analysis. The effect of the MQL system is clear for all the tests. Thus, the use of the MQL system leads to higher acceleration signals. In particular, at the lower feed rate, while at the higher feed rate its influence is less important.
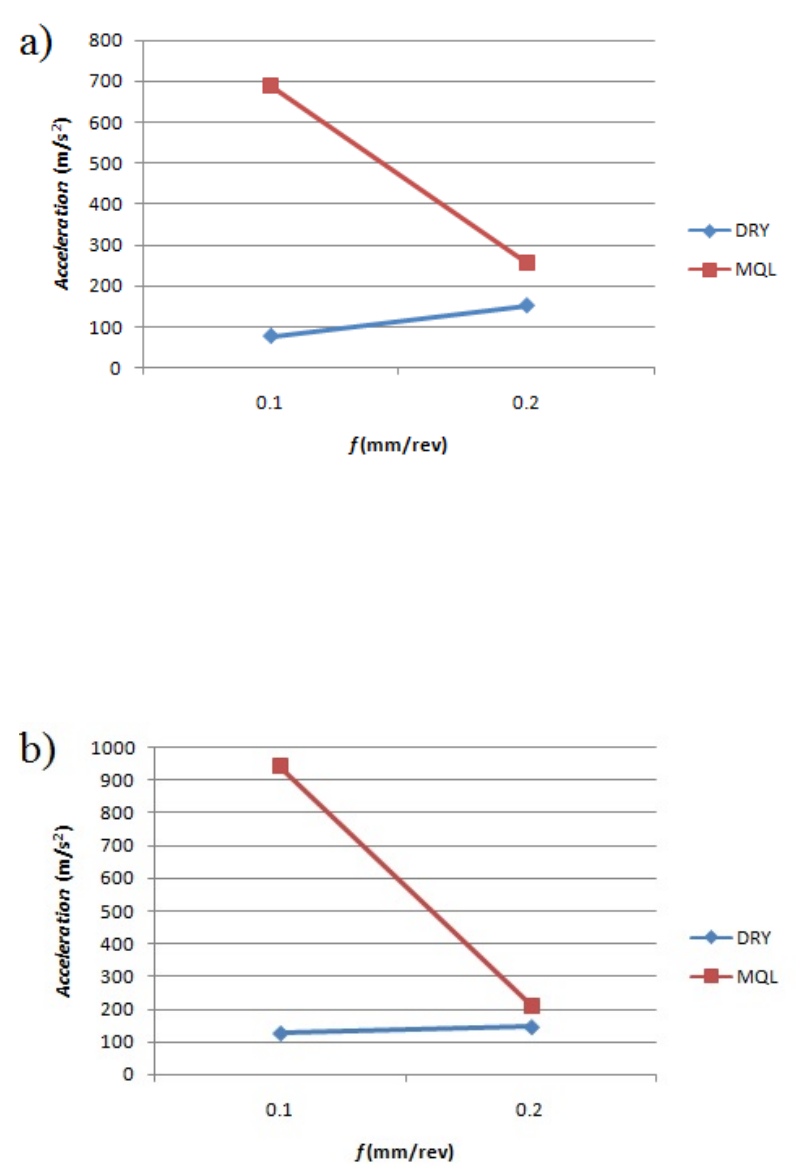


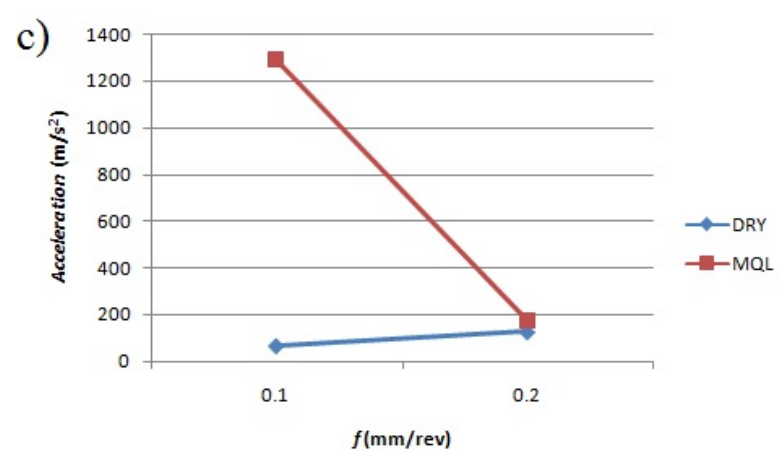

Fig. 5. Vibration versus feed rate for different cutting speeds: a) $\mathrm{i}=0 \mathrm{~mm}$, b) $\mathrm{i}=15 \mathrm{~mm}$ and c) $\mathrm{i}=30 \mathrm{~mm}$.

\subsection{Relation between the vibrations and the surface roughness}

In section 3.1, the relation between the vibrations and the feed rate, MQL flow rate and the type of the interruption was analysed. A clear dependency on the MQL flow rate and its interaction with feed rate was identified using statistical analysis; though the model developed did not explain completely the vibration signals measured. Next, the relation between the vibrations and surface quality is analysed. To study this relation, the results of surface roughness in terms of the arithmetical average roughness $(R a)$ measured for each test ( $R_{a 1}, R_{a 2}$ and $R_{a 3}$ for the workpieces with 0, 15 and 30 $\mathrm{mm}$ width interruption, respectively) are used. These results are the average of three measurements that were taken on different generatrix (with a $120^{\circ}$ separation) [18]. The average results are shown in Table 5.
Table 5.

Average surface roughness results.

\begin{tabular}{llll}
\hline Test & $R_{a 1}(\mu \mathrm{m})$ & $R_{a 2}(\mu \mathrm{m})$ & $R_{a 3}(\mu \mathrm{m})$ \\
\hline 1 & 2.83 & 2.78 & 2.86 \\
2 & 0.80 & 0.74 & 0.77 \\
3 & 2.81 & 2.68 & 2.72 \\
4 & 0.77 & 0.72 & 0.75 \\
5 & 3.04 & 3.10 & 2.93 \\
6 & 0.77 & 0.74 & 0.78 \\
7 & 3.02 & 2.93 & 3.04 \\
8 & 0.77 & $0.74 *$ & 0.76 \\
\hline
\end{tabular}

The surface roughness in the intermittent turning of magnesium at low speeds is mainly influenced by the feed rate. No influence of the workpiece interruptions and a limited effect of the use of MQL systems on the surface roughness were identified by Carou et al. [29]. Thus, to evaluate the relation of the surface roughness and the vibrations, the surface roughness is plotted versus the vibration in Fig. 6 and Fig. 7, corresponding to the dry machining and MQL cases, respectively.

The graphical representation allows identifying how the vibration results can be easily sorted by using the feed rate. Moreover, it is possible to identify two different trends in data. In dry machining, it is clear that as the vibration increases, the surface roughness also increases. So, the increase in the vibrations can be justified on the increase of the feed rate. When using the MQL system, a completely different trend is observed. As the vibration increases, the surface roughness diminishes. However, in the case of the feed rate of $0.1 \mathrm{~mm} / \mathrm{rev}$, it is possible to appreciate how there is a value that doesn't follow the trend. This fact can be result of experimental errors and it can be considered as an outlier value. The different effect of the feed rate depending on the environment used was also identified in the statistical analysis, considering that the interaction between feed rate and the MQL system was a significant source of variability. Clearly, the increase 
in the feed rate generates an increase in the surface roughness but not in the vibrations. So, the use of the MQL attenuates the vibrations in the intermittent turning of magnesium because of the lubricating effect of the MQL system. This effect was also identified by Zhong et al. [34] in the milling of the aluminium alloy 7050-T7451.

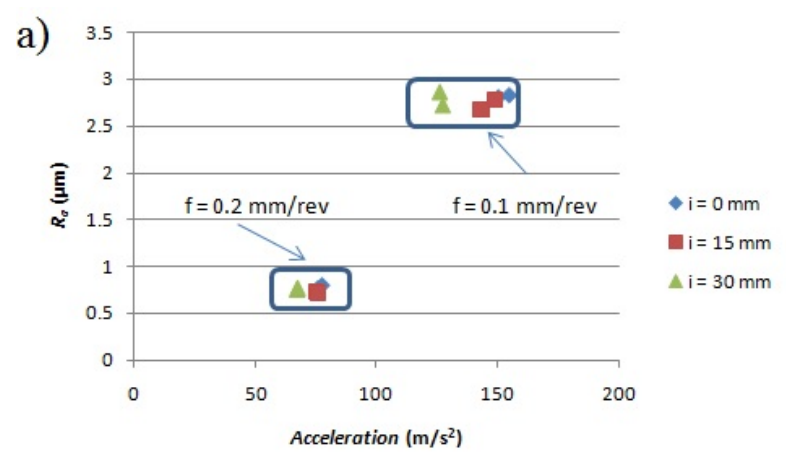

Fig. 6. Surface roughness versus vibration in dry machining tests for the three types of workpieces.

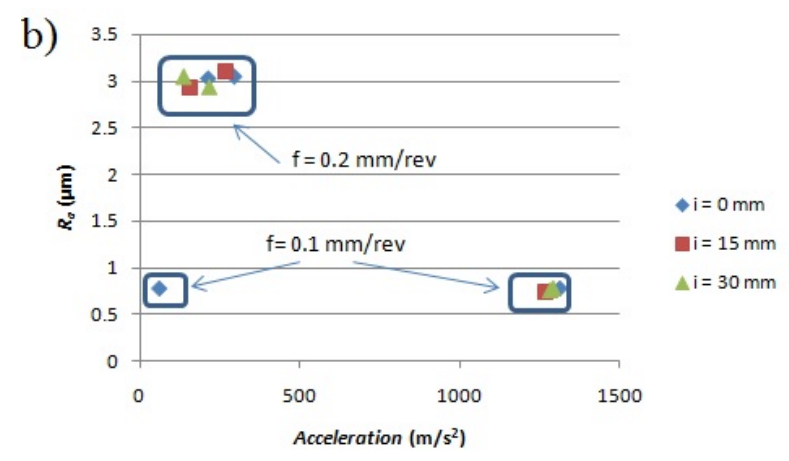

Fig. 7. Surface roughness versus vibration in MQL tests for the three types of workpieces.

Based on the obtained results, the vibrations can be a suitable indicator for surface roughness, especially, in the case of dry machining. This is possible because of the strong relation between the vibrations and feed rate. So, it is reasonable to expect that the appearance of vibrations on the feed direction could have effects on surface roughness. However, it should be interesting to analyse the influence of the vibrations in different directions on the surface roughness. In this sense, Upadhyay et al. [18] studied the influence of the vibrations on the surface roughness, identifying a correlation for both radial and tangential vibrations but not for the axial direction. In the case MQL systems, the relation seems to be more complex because the MQL flow rate plays an important role in the vibrations measured. This effect is higher at the lower feed rates, and, when increasing both feed rate and MQL flow rate, vibrations tend to diminish. Thus, further research on the conditions used in the MQL system: air pressure, nozzle positioning, flow rate, etc. is needed.

\section{CONCLUSIONS}

The vibrations in the intermittent turning of UNS M11917 magnesium alloy were analysed. The main conclusions of the study include the following:

- The vibration signal measured in the process depends greatly on the MQL flow rate and the feed rate. In addition, no significant influence of the type of interruption is identified.

- The effect of the feed rate on the vibration is different depending on the cutting environment used. In particular, the increase of the feed rate leads to higher vibrations in the case of dry machining tests, while, by contrast, to lower vibrations when using the MQL system. So, the use of the MQL system attenuates the vibrations.

- $\quad$ Regarding the use of the MQL system, the higher vibrations are measured when machining with this environment, especially, at the lower feed rates.

- The relation between surface roughness and the vibrations measured is clear in the dry machining tests. Thus, when higher vibrations are observed also higher surface roughness is measured. The opposite happens when the MQL system is used. 
- Finally, it was observed that the relation between surface roughness and vibrations is clearly defined by the feed rate.

\section{ACKNOWLEDGEMENTS}

The authors would like to thank to the University of the Aveiro for providing the facilities and equipment to perform the tests, and the support given by the “Machining \& Tribology (MACTRIB)” (University of Aveiro) and "Industrial Production and Manufacturing Engineering (IPME)” (Universidad Nacional de Educación a Distancia- UNED) research groups and the Centre for Mechanical Technology and Automation (TEMA, University of Aveiro). In addition, they thank to Grupo Antolín Magnesio S.L. the transfer of part of the material used in this study.

The study had the support of the Spanish Ministry of Science and Innovation, and the Industrial Engineering School-UNED by the funding of the projects DPI201458007-R and REF2016-ICF05, respectively.

\section{REFERENCES}

[1] J.P. Davim, C.A.C. António, Optimal drilling of particulate metal matrix composites based on experimental and numerical procedures, Int. J. Mach. Tools Manuf. 41(1) (2001) 21-31.

[2] B.L. Mordike, T. Ebert, Magnesium properties — applications — potential, Mat. Sci. Eng. A 302 (2001) 37-45.

[3] L. Dobrzański, T. Tański, L. Č́́žek, Z. Brytan, Structure and properties of magnesium cast alloys, J. Mater. Process. Technol. 192-193 (2007) 567-574.
[4] Z. Trojanová, V. Gärtnerová, A. Jäger, A. Námešný, M. Chalupová, P. Palček, P. Lukáč, Mechanical and fracture properties of an AZ91 Magnesium alloy reinforced by $\mathrm{Si}$ and $\mathrm{SiC}$ particles, Compos. Sci. Technol. 69(13), (2009) 2256-2264.

[5] L.D. Scintilla, L. Tricarico, Experimental investigation on fiber and $\mathrm{CO}_{2}$ inert gas fusion cutting of AZ31 magnesium alloy sheets, Opt. Laser Technol. 46 (2013) 42-52.

[6] D. Carou, E.M. Rubio, J.P. Davim, Machinability of Magnesium and Its Alloys: A Review, In: J.P. Davim (Ed.), Traditional Machining Processes, Springer, 2014, pp 133-152.

[7] S. Dinesh, V. Senthilkumar, P. Asokan, D. Arulkirubakaran, Effect of cryogenic cooling on machinability and surface quality of biodegradable ZK60 Mg alloy, Mater. Des. 87 (2015) 1030-1036.

[8] D. Carou, E.M. Rubio, J.P. Davim, Analysis of ignition risk in intermittent turning of UNS M11917 magnesium alloy at low cutting speeds based on the chip morphology, Proc. Inst. Mech. Eng. B J. Eng. Manuf. 229(2) (2015) 365-371.

[9] A. Thakur, S. Gangopadhyay, State-of-the-art in surface integrity in machining of nickelbased super alloys, Int. J. Mach. Tools Manuf. 100 (2016) 25-54.

[10] Y. Gao, R. Sun, Y. Chen, J. Leopold, Analysis of chip morphology and surface topography in 
modulation assisted machining, Int. J. Mech. Sci. 111-112 (2016) 88-100.

[11] S.J. Zhang, S. To, S.J. Wang, Z.W. Zhu, A review of surface roughness generation in ultra-precision machining, Int. J. Mach. Tools Manuf. 91 (2015) 76-95.

[12] I.T. Al-Zaharnah, Suppressing vibrations of machining processes in both feed and radial directions using an optimal control strategy: The case of interrupted cutting, J. Mater. Process. Technol. 172(2) (2006) 305-310.

[13] M. Thomas, Y. Beauchamp, Statistical investigation of modal parameters of cutting tools in dry turning, Int. J. Mach. Tools Manuf. 43(11) (2003) 1093-1106.

[14] E.C. Lee, C.Y. Nian, Y.S. Tarng, Design of a dynamic vibration absorber against vibrations in turning operations, J. Mater. Process. Technol. 108 (2001) 278-285.

[15] M. Subramanian, M. Sakthivel, K. Sooryaprakash, R. Sudhakaran, Optimization of end mill tool geometry parameters for Al7075-T6 machining operations based on vibration amplitude by response surface methodology, Measurement 46(10) (2013) 4005-4022.

[16]A. Devillez, D. Dudzinski, Tool vibration detection with eddy current sensors in machining process and computation of stability lobes using fuzzy classifiers, Mech. Syst. Signal Process. 21 (2007) 441-456.
[17]A. Stoic, F. Pusavec, J. Kopac, Cutting disturbances influenced by variations in contact surface geometry, Mach. Sci. Technol. 13(4) (2009) 516-528.

[18] V. Upadhyay, P.K. Jain, N.K. Mehta, Inprocess prediction of surface roughness in turning of $\mathrm{Ti}-6 \mathrm{Al}-4 \mathrm{~V}$ alloy using cutting parameters and vibration signals, Measurement 46(1) (2013) 154-160.

[19]Z. Hessainia, A. Belbah, M.A. Yallese, T. Mabrouki, J.-F. Rigal, On the prediction of surface roughness in the hard turning based on cutting parameters and tool vibrations, Measurement 46(5) (2013) 1671-1681.

[20] O.B. Abouelatta, J. Mádl, Surface roughness prediction based on cutting parameters and tool vibrations in turning operations, J. Mater. Process. Technol. 118 (2001) 269-277.

[21] A.E. Diniz, D.M. Gomes, A. Braghini, Turning of hardened steel with interrupted and semiinterrupted cutting, J. Mater. Process. Technol. 159(2) (2005) 240-248.

[22] G. Chakraverti, P.C. Pandey, N.K. Mehta, Analysis of tool temperature fluctuation in interrupted cutting, Precis. Eng. 6(2) (1984) 99-105.

[23]D. Carou, E.M. Rubio, J.P. Davim, Discontinuous cutting: failure mechanisms, tool materials and temperature study - A review, Rev. Adv. Mater. Sci. 38 (2014) 110124. 
[24] Z. Pu, J.C. Outeiro, A.C. Batista, O.W. Dillon

Jr, D.A. Puleo, I.S. Jawahir, Enhanced surface integrity of AZ31B Mg alloy by cryogenic machining towards improved functional performance of machined components, Int. J. Mach. Tools Manuf. 56 (2012) 17-27.

[25] S. Ramesh, R. Viswanathan, S. Ambika, Measurement and optimization of surface roughness and tool wear via grey relational analysis, TOPSIS and RSA techniques, Measurement 78 (2016) 63-72.

[26] D. Carou, E.M. Rubio, J.P. Davim, A note on the use of the minimum quantity lubrication (MQL) system in turning, Ind. Lub. Tribol. 67(3) (2015) $256-261$.

[27] N.R. Dhar, M. Kamruzzaman, M. Ahmed, Effect of minimum quantity lubrication (MQL) on tool wear and surface roughness in turning AISI-4340 steel, J. Mater. Process. Technol. 172(2) (2006) 299-304.

[28] J.P. Davim, V.N. Gaitonde, S.R. Karnik, Investigations into the effect of cutting conditions on surface roughness in turning of free machining steel by ANN models, J. Mater. Process. Technol. 205 (2008) 16-23.

[29] D. Carou, E.M. Rubio, C.H. Lauro, J.P. Davim, Experimental investigation on surface finish during intermittent turning of UNS M11917 magnesium alloy under dry and near dry machining conditions, Measurement 56 (2014) 136-154.

[30] E.M. Rubio, M. Villeta, D. Carou, A. Saá, Comparative analysis of sustainable cooling systems in intermittent turning of magnesium pieces, Int J Precis Eng Manuf. 15(5), (2014) 929-940.

[31] M. Siddhpura, R. Paurobally, A review of chatter vibration research in turning, Int. J. Mach. Tools Manuf. 61 (2012) 27-47.

[32] D.C. Montgomery, Design and analysis of experiments, fifth ed., John Wiley \& Sons, New York, 2001.

[33] J.P. Davim, L. Figueira, Machinability evaluation in hard turning of cold work tool steel (D2) with ceramic tools using statistical techniques, Mater. Des. 28(4) (2007) 11861191.

[34] W. Zhong, D. Zhao, X. Wang, A comparative study on dry milling and little quantity lubricant milling based on vibration signals, Int. J. Mach. Tools Manuf. 50 (2010) 1057-1064. 